\title{
ZnO/Mg-Al Layered Double Hydroxides as a Photocatalytic Bleaching of Methylene Orange - A Black Box Modeling by Artificial Neural Network
}

\author{
Seyed Ali Hosseini*, Mansor Akbari \\ Department of Applied Chemistry, Faculty of Chemistry, Urmia University, Urmia, Iran
}

Received: 22 $2^{\text {nd }}$ January 2016; Revised: 14th March 2016; Accepted: 15 th March 2016

\section{Abstract}

The paper reports the development of $\mathrm{ZnO}-\mathrm{MgAl}$ layered double hydroxides as an adsorbent-photo catalyst to remove the dye pollutants from aqueous solution and the experiments of photo catalytic study were designed and modeled by response surface methodology (RSM) and artificial neural network (ANN). The co-precipitation and urea methods were used to synthesize the $\mathrm{ZnO}-\mathrm{MgAl}$ layered double hydroxides and FT-IR, XRD and SEM analysis were done for characterization of the catalyst.The performance of the ANN model was determined and showed the efficiency of the model in comparison to the RSM method to predict the percentage of dye removal accurately with determination coefficient $\left(\mathrm{R}^{2}\right)$ of 0.968 . The optimized conditions were obtained as follows: $600{ }^{\circ} \mathrm{C}, 120 \mathrm{~min}, 0.05 \mathrm{~g}$ and $20 \mathrm{ppm}$ for the calcination temperature, irradiation time, catalyst amount and dye pollutant concentration, respectively. Copyright (C) 2016 BCREC GROUP. All rights reserved

Keywords: layered double hydroxide; photo catalyst; artificial neural network; response surface methodology; nano composite

How to Cite: Hosseini, S.A., Akbari, M. (2016). ZnO/Mg-Al Layered Double Hydroxides as a Photocatalytic Bleaching of Methylene Orange - A Black Box Modeling by Artificial Neural Network. Bulletin of Chemical Reaction Engineering \& Catalysis, 11 (3): 299-315 (doi: 10.9767/bcrec.11.3.570.299-315)

Permalink/DOI: http://doi.org/10.9767/bcrec.11.3.570.299-315

\section{Introduction}

One of the most significant current environmental problems is wastewater treatment and depuration [1]. This is a very difficult task due to the variety of contaminants present in such wastes [2]. In recent year's dyes and pigments as a wastewater from food and textile industries took a lot of attention to hinder their releasing to the environment and degradation of them because of the adverse effect on environ-

* Corresponding Author.

E-mail: s_ali_hosseini@yahoo.com (S.A. Hosseini)

Telp: +98-44-31942026, Fax: +98-44-32755294 ment specifically in aqueous milieu [3]. In the textile industry, dyeing process generated a large volume of wastewater containing most unreacted colored dyestuffs [4]. The percentage of even a small amount of dye in water is highly visible and affects the water transparency and gas solubility of water bodies [5]. A lot of researches and studies were done on adsorption of dye pollutants like: activated carbon, zeolites, etc. But all of them were like a mediate that transfer pollution from one medium to another [2]. Beside these materials solve the existing problem but causes a bigger insoluble environmental problem later on [6,7].

In order to avoid deterioration of water resources and to reuse the treated wastewater 
from a wastewater treatment plant (WWTP), taking also into consideration that recalcitrant organic compounds in wastewaters are insufficiently removed by conventional chemical and biological treatments, advanced oxidation processes (AOPs) are being studied as an alternative to traditional methods $[3,8,9]$.

AOPs are particularly effective as methods for removing organic pollutants from water because they can destroy hazardous contaminants, and not simply transfer them to another phase as do conventional treatment techniques [3]. AOPs are based on the generation of highly reactive species, such as hydroxyl radicals $(\cdot \mathrm{OH})$ that can oxidize a broad range of pollutants, such as phenols, pesticides, pharmaceuticals and dyes quickly and non-selectively [1012]. Layered double hydroxides (LDHs), also known as hydrotalcite-like materials or anionic clays, are natural or synthetic mixed metal hydroxides relatively simple and cheap to prepare on both laboratory and industrial scales [13]. LDHs possessed a layered structure of general formula $\left[\mathrm{M}(\mathrm{II})_{1-\mathrm{x}} \mathrm{M}(\mathrm{III})_{\mathrm{x}}(\mathrm{OH})_{2}\right]^{\mathrm{x}+}\left(\mathrm{A}^{\mathrm{n}}{ }_{\mathrm{x} / \mathrm{n}}\right)$, where $\mathrm{M}^{2+}$ and $\mathrm{M}^{3+}$ are divalent $\left(\mathrm{Mg}^{2+}, \mathrm{Fe}^{2+}, \mathrm{Co}^{2+}\right.$, $\left.\mathrm{Cu}^{2+}, \mathrm{Ni}^{2+}, \mathrm{Zn}^{2+}\right)$ and trivalent $\left(\mathrm{Al}^{3+}, \mathrm{Cr}^{3+}, \mathrm{In}^{3+}\right.$, $\mathrm{Mn}^{3+}, \mathrm{Ga}^{3+}, \mathrm{Fe}^{3+}$ ) metal ions, respectively; $\mathrm{A}$ is an intercalate anion $\left(\mathrm{CO}_{3}{ }^{2-}, \mathrm{SO}_{4}{ }^{2-}, \mathrm{NO}_{3}{ }^{-}, \mathrm{F}^{-}\right.$, $\mathrm{Cl}^{-}$). The positive charge generated by the substitution of a part of the divalent cations by trivalent cations in the brucite-like layers was compensated by the presence of anions in the interlayer space [14].

LDHs has exhibited its promising application in the adsorption of dye anions due to its high surface area and the anion exchange property of its host layers [8]. Most of the dyes and pigments have at least an azo band $(\mathrm{N}=\mathrm{N})$ in their molecular structure that can be used to enter to the interlayer space of layered double hydroxide. But as mention above these kind of adsorptive material can be used as a temporary solution [4,15]. $\mathrm{ZnO}-\mathrm{MgAl}$ layered double hydroxides show a promising way in adsorption and photo catalytic degradation of organic pollution [16]. ZnO-MgAl layered double hydroxide's application enhances by their capability in dye degradation by using a low energy irradiations like UV-C and visible light $[17,18]$. This property increase a lots of attention for using them as a promising method in both adsorption and photo catalytic degradation [17,19].

In order to enhance photo catalytic degradation design of experiments was done by selecting four effective factors in dye degradation using $\mathrm{ZnO}-\mathrm{MgAl}$ layered double hydroxides [20,21]. Photo catalytic oxidation efficiency is dependent on a number of parameters such as the reactor configuration, UV light intensity, initial analyte concentration, reaction time, $\mathrm{pH}$, mass of catalyst, flow rate, etc. [3]. To optimize the effective parameters with the minimum number of experiments, the application of experimental design methodologies can be useful [4]. Response Surface Methodology (RSM) and Artificial Neural Networks (ANNs) are powerful mathematical methods suitable for modeling and optimizing chemical reactions and/or industrial processes [22]. In fact, these modeling techniques approximate the functional relationships between input variables (experimental operational parameters) and the output (response) of the process using experimental data [23]. Afterwards, the models are used to estimate the optimal settings of input variables to maximize or minimize the response $[24,25]$. RSM and ANNs have been widely applied to the modeling and optimization of photo catalytic oxidation processes related to the degradation of individual pollutants such as dyes, pesticides, pharmaceuticals and wastewater streams such as dyestuff, power station effluents, etc. [26-32,50].

To the best of our know-ledge, there are no studies dealing with the comparison of RSM and ANN modeling methods for the optimization of photo catalytic degradation of organic dyes like Methyl Orange (MO) from aqueous solution [34]. The aim of this work was to study of the photo catalytic degradation of dye pollutants from aqueous solutions over eco-friendly $\mathrm{ZnO}-\mathrm{MgAl}$ layered double hydroxide in more details by gathering some information from artificial neural network (ANN) and response surface methodology as tools. In order to save the time and costs of study the experiments were designed by Box-Behnken of response surface methodology in order to reduce the number of experiments. Artificial neural network (ANN) was used as a black box tool to model and optimize the photo catalytic system. The synthesized LDH photo catalyst was characterized by XRD, FTIR, and SEM.

\section{Materials and Method}

All chemicals used in this study were of analytical grade and used without any purification. $\mathrm{Mg}\left(\mathrm{NO}_{3}\right)_{2} \cdot 6 \mathrm{H}_{2} \mathrm{O}, \mathrm{Al}\left(\mathrm{NO}_{3}\right) \cdot 9 \mathrm{H}_{2} \mathrm{O}$, Urea, Zinc acetate, sodium carbonate, methyl orange and sodium hydroxide were obtained from Merck (Darmstadt, Germany).

\subsection{Sample preparation}

The Mg-Al LDHs (molar ratios $\mathrm{Mg} / \mathrm{Al}=2$ ) was prepared by co-precipitation of magnesium 
and aluminum salts from homogeneous solution. A typical synthetic procedure is as follows: $6.4 \mathrm{~g} \quad \mathrm{Mg}\left(\mathrm{NO}_{3}\right)_{2} \cdot 6 \mathrm{H}_{2} \mathrm{O}$ and $4.6 \mathrm{~g}$ $\left.\mathrm{Al}\left(\mathrm{NO}_{3}\right)_{3.9} . \mathrm{H}_{2} \mathrm{O}\right)$ dissolved in $100 \mathrm{~mL}$ of deionized water under vigorous stirring. After $10 \mathrm{~min}$, solution B contain $1.125 \mathrm{~g} \mathrm{Na}_{2} \mathrm{CO}_{3}$ and $4 \mathrm{~g} \mathrm{NaOH}$ were added drop wise in the above homogenous solution, and kept the mixture solution under constant magnetic stirring for 3 min at room temperature. Then the solid was separated by vacuum filter and washed thoroughly with water and finally dried overnight at $70 \circ \mathrm{C}$.

For synthesis of $\mathrm{ZnO}-\mathrm{MgAl}$ layered double hydroxides, $\left(\mathrm{CH}_{3} \mathrm{COO}\right)_{2} \mathrm{Zn} \cdot 2 \mathrm{H}_{2} \mathrm{O}, \mathrm{CO}\left(\mathrm{NH}_{2}\right)_{2}$ and the prepared $\mathrm{MgAl}-\mathrm{LDH}$ s were used as the raw materials. In order to obtain the precipitation of metal hydrous oxides with uniform size, urea was used as a basic precipitating agent. The urea aqueous solution release hydroxide and carbon dioxide slowly upon the heating over 60 $\circ \mathrm{C}$, the hydroxide promotes the hydrolysis of the metal salt solution is generally called homogeneous precipitation.

The $3 \mathrm{~g}\left(\mathrm{CH}_{3} \mathrm{COO}\right)_{2} \mathrm{Zn} .2 \mathrm{H}_{2} \mathrm{O}$ mixed $10 \mathrm{~g}$ urea was dissolved in $100 \mathrm{~mL}$ of the distilled water under room temperature to a clear solution. A 3:1 mass ratio of $\mathrm{ZnO} / \mathrm{MgAl}$ layered double hydroxides selected because of the best removal percentage in the same condition $[11,17]$. So, the $1 \mathrm{~g}$ MgAl layered double hydroxide synthesized before, added to suspension containing of zinc salt and urea and vigorously stirred for several hours in order to make the solution to be dispersed evenly. Then, the suspension was heated to $60 \circ \mathrm{C}$ and kept at the temperature for about $3 \mathrm{~h}$ under magnetic stirring in order to gain a uniform solution. The product was then filtered by vacuum filter and washed several times by deionized water to purify the crystalline.
For preparation of the methyl orange solutions with different concentrations in $\mathrm{ppm}$ scale mg of the methyl orange was added to $1000 \mathrm{~mL}$ of distilled water and was vigorously stirred to gain a uniform Dye solution with different concentrations.

\subsection{Photo catalyst characterization}

$\mathrm{X}$-ray diffraction (XRD) studies were carried out on a Siemens D500 diffract meter working with $\mathrm{Ka}$ line of copper $(\lambda=0.154 \mathrm{~nm})$. Measurement of the samples was carried out in the range $2 \theta$ of $2.5-50^{\circ}$. The mean crystal sizes were estimated using the Scherer equation, $D=K \lambda / \beta \cos \theta$, where $K=0.89, \lambda=0.15418 \mathrm{~nm}, \beta$ is the half peak width of the $\mathrm{X}$-ray reflection and $\theta$ is the diffraction angle. Infrared (IR) spectra were recorded with a Bruker 27 FT-IR spectrometer using the Universal ATR Accessory in the range from 3650 to $400 \mathrm{~cm}^{-1}$ with $4 \mathrm{~cm}^{-1}$ resolution. Furthermore, the shape and size of the synthesized particles were determined via scanning electron microscopy (SEM) by Hitachi s-4200 instrument with precoating samples with gold.

\subsection{Determination of percentage of the dye pollution from the aqueous solution}

In order to testify just photo catalytic property batch mode selected for dye degradation from aqueous solution using $\mathrm{ZnO}$ MgAl layered double hydroxide. A sample of the catalyst with amounts that were designed by Minitab 17 was added to the dye containing solution in room temperature and vigorously stirring. After 20 minutes adsorbed dye by MgAl-LDH was determined by UV/visible spectrophotometer. Then the suspension was irradiated for specified time (as planned by Minitab 17) under UV-C (15 W) in photo

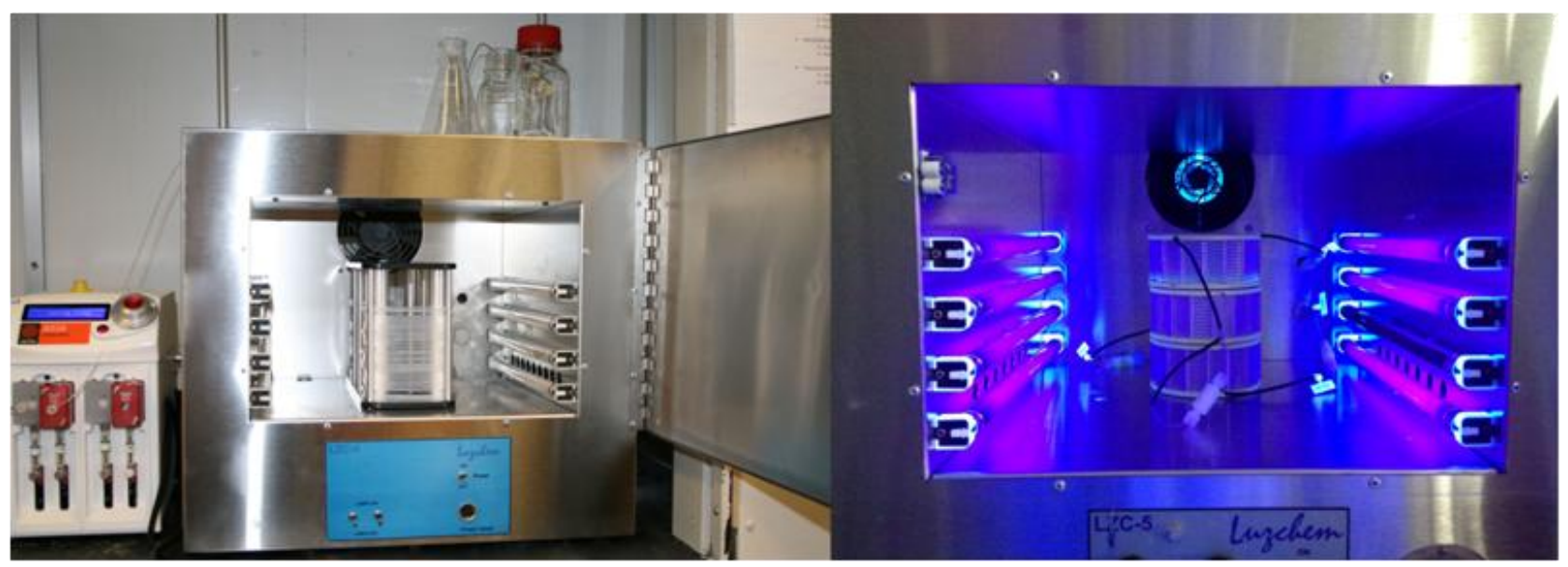

Figure 1. Scheme of the photo reactor used in this experiment 
reactor. The photo reactor with vigorous stirring system as shown in Figure 1 was used to investigate the photo catalytic performance of the synthesized photo catalyst during the experiment. The volume of reactor was $50 \mathrm{ml}$ of Dye solution with different concentration. The lames used in this experiment were $15 \mathrm{~W}-\mathrm{UV}-\mathrm{C}$ lamps made in Philips (Germany).

Then the suspension was centrifuged and eventually analyzed by UV/visible spectrophotometer (TG $80+$ ) made in United Kingdom. The amount of dye removal (\%) was calculated in Equation (1).

$$
\text { Amount of dye removal }(\%)=\left(C_{0^{-}} C_{t}\right) / C_{0} \times 100
$$

where $C_{0}$ is the initial concentration after absorption $(\mathrm{mm})$ of the dye solution and $C_{t}$ is the concentration after specified time. The ranges of the variables for design of the experiment and modeling are listed as follows: (a) calcination temperature of $300-600{ }^{\circ} \mathrm{C}$; (b) catalyst amount: 0.01-0.05 g; (c) dye concentration of 20-60 ppm; (d) time of 30-120 $\min$.

\subsection{Experimental design, modeling, optimization by Response Surface Methodology (RSM) and Artificial Neural Networks (ANNs)}

To find the optimum conditions for degradation of MO, a Box Behnken design (BBD) was adopted to evaluate the combined effect of four factors (variables), i.e. calcination temperature, the amount of catalyst, irradiation time and dye pollutant concentration. For four variables $(n=4)$ and two levels (high (+) and low (-)) and replicate option, the total number of experiments was 54 (shown in Table 1). The data set obtained from BBD was used for the optimization of the response of MO photo catalytic degradation percentage. The Response Surface Methodology (RSM) and Artificial Neural Networks (ANNs) were used to fit experimental data. In the RSM, the responses can be simply related to chosen factors, by first-order or second-order polynomial models. The first-order model uses a low-order polynomial model, which is appropriate for describing a flat surface, according to the Equation (2).

$$
y=\beta_{0} \sum_{i=1}^{k} \beta_{i} x_{i}+\varepsilon
$$

where $y$ is the predicted response, $\beta_{0}$ is the constant term, $\beta_{i}$ represents the coefficients of the linear parameters, $x_{i}$ represents the variables and $\varepsilon$ is the random error.

If interaction terms are included, the firstorder model can then be represented as follows:

$$
y=\beta_{0} \sum_{i=1}^{k} \beta_{i} x_{i}+\sum_{1 \leq i \leq j}^{k} \beta_{i} x_{i}+\varepsilon
$$

where $\beta_{i j}$ represents the coefficients of the interaction parameters $x_{i}$ and $x_{j}$. A second-order model may be studied in order to locate the optimum point. A second-order model is given in Equation (4).

$$
y=\beta_{0} \sum_{i=1}^{k} \beta_{i} x_{i}+\sum_{i=1}^{k} \beta_{i i i} x_{i i}+\sum_{1 \leq i \leq j}^{k} \beta_{i j} x_{i} x_{j}+\varepsilon
$$

where $\beta_{i i}$ represents the coefficients of the quadratic parameter [26, 27, 30,31].

Statistical analysis was performed using the software package Minitab v.17 and a regression model was proposed. Analysis of variance (ANOVA) was performed based on the proposed model to find the interaction between the process variables and the response. The quality of the fit for the polynomial model was expressed with the coefficient of determination $\left(\mathrm{R}^{2}, \mathrm{R}^{2}\right.$ adj. $)$, and statistical significance was checked by the $F$-value, $P$-value and adequate precision in the same program. Model terms were selected or rejected based on the probability value with $95 \%$ confidence level $(P>$ 0.05). Finally, three-dimensional response surface plots and contour plots were drawn in order to visualize the individual and the interaction effects of the independent variables on MO degradation [35,36].

On the other hand, ANNs are computational model programs which can approximate complex nonlinear relationships existing between independent (ANN input) and dependent (ANN output) variables to an arbitrary degree of accuracy [37]. These relationships are achieved through learning (or training) of data network. The neural network structure is constructed from hundreds of single units, called artificial neurons, which are connected with coefficients (weights). The neurons are sorted in an input layer, hidden layers (one or more) and an output layer and each of them has weighted inputs, activation function and one output. Neural network 
Table 1. The 4-factor Box Behnken design matrix (independent variables and their coded and actual levels; calcination temperature $\left({ }^{\circ} \mathrm{C}\right)$, dye concentration $(\mathrm{ppm})$, catalyst amount $(\mathrm{mg})$ and irradiation time (min) and the experimental results (degradation of MO (\%)) from aqueous solution

\begin{tabular}{|c|c|c|c|c|c|}
\hline Run & Calcin-Temp & Dye & $\mathrm{LDH}$ & Time & Experimental \\
\hline 1 & $0(450)$ & $0(40)$ & $0(0.03)$ & $0(85)$ & 75.9824 \\
\hline 2 & $0(450)$ & $0(40)$ & $1(0.05)$ & $1(120)$ & 68.9426 \\
\hline 3 & $0(450)$ & $0(40)$ & $-1(0.01)$ & $1(120)$ & 57.9137 \\
\hline 4 & $0(450)$ & $1(60)$ & $0(0.03)$ & $-1(30)$ & 51.9625 \\
\hline 5 & $0(450)$ & $0(40)$ & $0(0.03)$ & $0(85)$ & 71.6591 \\
\hline 6 & $1(600)$ & $0(40)$ & 1(0.05) & $0(85)$ & 86.9731 \\
\hline 7 & $0(450)$ & $0(40)$ & $1(0.05)$ & $-1(30)$ & 56.9154 \\
\hline 8 & $-1(300)$ & $-1(20)$ & $0(0.03)$ & $0(85)$ & 40.6249 \\
\hline 9 & $0(450)$ & $1(60)$ & $-1(0.01)$ & $0(85)$ & 50.8364 \\
\hline 10 & $-1(300)$ & $0(40)$ & $0(0.03)$ & $-1(30)$ & 31.021 \\
\hline 11 & $0(450)$ & $0(40)$ & $0(0.03)$ & $0(85)$ & 76.4927 \\
\hline 12 & $-1(300)$ & $0(40)$ & $-1(0.01)$ & $0(85)$ & 35.8591 \\
\hline 13 & $0(450)$ & $1(60)$ & $0(0.03)$ & $-1(30)$ & 51.9628 \\
\hline 14 & $0(450)$ & $1(60)$ & $0(0.03)$ & $1(120)$ & 61.3246 \\
\hline 15 & $1(600)$ & $0(40)$ & $-1(0.01)$ & $0(85)$ & 65.8572 \\
\hline 16 & $0(450)$ & $0(40)$ & $-1(0.01)$ & $-1(30)$ & 48.9274 \\
\hline 17 & $0(450)$ & $0(40)$ & $-1(0.01)$ & $-1(30)$ & 45.5628 \\
\hline 18 & $-1(300)$ & $0(40)$ & $0(0.03)$ & $-1(30)$ & 31.6821 \\
\hline 19 & $0(450)$ & $-1(20)$ & $0(0.03)$ & $-1(30)$ & 58.6904 \\
\hline 20 & $-1(300)$ & $1(60)$ & $0(0.03)$ & $0(85)$ & 37.2109 \\
\hline 21 & $0(450)$ & $0(40)$ & $-1(0.01)$ & $1(120)$ & 57.9319 \\
\hline 22 & $0(450)$ & $0(40)$ & $0(0.03)$ & $0(85)$ & 71.7439 \\
\hline 23 & $1(600)$ & $0(40)$ & $0(0.03)$ & $-1(30)$ & 63.8276 \\
\hline 24 & $-1(300)$ & $0(40)$ & $1(0.05)$ & $0(85)$ & 37.848 \\
\hline 25 & $-1(300)$ & $-1(20)$ & $0(0.03)$ & $0(85)$ & 40.6205 \\
\hline 26 & $0(450)$ & $0(40)$ & 1(0.05) & $-1(30)$ & 44.6852 \\
\hline 27 & $0(450)$ & $-1(20)$ & $0(0.03)$ & $-1(30)$ & 50.7348 \\
\hline 28 & $1(600)$ & $-1(20)$ & $0(0.03)$ & $0(85)$ & 85.251 \\
\hline 29 & $0(450)$ & $-1(20)$ & $0(0.03)$ & $1(120)$ & 77.2965 \\
\hline 30 & $0(450)$ & $0(40)$ & $1(0.05)$ & $1(120)$ & 68.5201 \\
\hline 31 & $0(450)$ & $1(60)$ & 1(0.05) & $0(85)$ & 52.4682 \\
\hline 32 & $0(450)$ & $0(40)$ & $0(0.03)$ & $0(85)$ & 68.3965 \\
\hline 33 & $1(600)$ & $0(40)$ & $0(0.03)$ & $1(120)$ & 91.2057 \\
\hline 34 & $1(600)$ & $0(40)$ & $0(0.03)$ & $1(120)$ & 90.4195 \\
\hline 35 & $0(450)$ & $1(60)$ & 1(0.05) & $0(85)$ & 52.4682 \\
\hline 36 & $1(600)$ & $0(40)$ & $0(0.03)$ & $-1(30)$ & 63.8276 \\
\hline 37 & $1(600)$ & $0(40)$ & $-1(0.01)$ & $0(85)$ & 68.2672 \\
\hline 38 & $0(450)$ & $0(40)$ & $0(0.03)$ & $0(85)$ & 75.6387 \\
\hline 39 & $0(450)$ & $-1(20)$ & $1(0.05)$ & $0(85)$ & 78.0918 \\
\hline 40 & $0(450)$ & $-1(20)$ & 1(0.05) & $0(85)$ & 82.1076 \\
\hline 41 & $1(600)$ & $1(60)$ & $0(0.03)$ & $0(85)$ & 80.4792 \\
\hline 42 & $0(450)$ & $1(60)$ & $0(0.03)$ & $1(120)$ & 52.6717 \\
\hline 43 & $0(450)$ & $-1(20)$ & $-1(0.01)$ & $0(85)$ & 60.3109 \\
\hline 44 & $-1(300)$ & $0(40)$ & $-1(0.01)$ & $0(85)$ & 30.2014 \\
\hline 45 & $0(450)$ & $1(60)$ & $-1(0.01)$ & $0(85)$ & 50.8369 \\
\hline 46 & $-1(300)$ & $0(40)$ & $0(0.03)$ & $1(120)$ & 45.6325 \\
\hline 47 & $1(600)$ & $0(40)$ & 1(0.05) & $0(85)$ & 70.5091 \\
\hline 48 & $-1(300)$ & $1(60)$ & $0(0.03)$ & $0(85)$ & 43.6502 \\
\hline 49 & $0(450)$ & $-1(20)$ & $0(0.03)$ & $1(120)$ & 72.1198 \\
\hline 50 & $1(600)$ & $1(60)$ & $0(0.03)$ & $0(85)$ & 76.6395 \\
\hline 51 & $-1(300)$ & $0(40)$ & 1(0.05) & $0(85)$ & 40.8734 \\
\hline 52 & $-1(300)$ & $0(40)$ & $0(0.03)$ & $1(120)$ & 45.7192 \\
\hline 53 & $1(600)$ & $-1(20)$ & $0(0.03)$ & $0(85)$ & 82.6249 \\
\hline 54 & $0(450)$ & $-1(20)$ & $-1(0.01)$ & $0(85)$ & 62.6715 \\
\hline
\end{tabular}


training is achieved when the error function, which measures the difference between calculated and desired output values, are minimized. After the training process, the ANNs can predict the desired information [3842]. The topology of an ANN is determined by the number of its layers, number of neurons in each layer and the nature of learning algorithms and transfer functions. Finding the best ANN topology is the most important step in the development of a model. In the present study the feed-forward multilayered perceptron (MLP) ANN was tested [43].

\subsection{Training and validation of ANN}

The Levenberg-Marquardt method is a standard technique used to solve nonlinear least squares problems. Least squares problems arise when fitting a parameterized function to a set of measured data points by minimizing the sum of the squares of the errors between the data points and the function. The algorithm is based on gradient descent method to calculate and update the values of weights and biases in the network, by using a function optimization technique to reduce the error in the training data set. Notably, LevenbergMarquardt algorithm is particularly efficient in minimizing sum of square errors for non-linear functions, and therefore its performance has been measured by root mean squared error. The connection between inputs, hidden and output layers consist of weights $(w)$ and biases (b) that are considered parameters of the neural network (NN) [44]. The neurons in the input layer simply introduce the scaled input data via $w$ to the hidden layer. The neurons in the hidden layer carried out two tasks. First, they sum up the weighted inputs to neurons, including $b$, as shown by the following equation:

$$
s u m=\sum x_{i} w_{i}+b
$$

where $x_{i}$ is the input parameter. The weighted output is then passed through a transfer function. In this study, tansig was used as a transfer function between input and hidden layer, while purelin was used as a transfer function between hidden and output layer, shown by the following equations:

$$
\operatorname{Tansig}(\text { sum })=\frac{1-\exp (- \text { sum })}{1+\exp (- \text { sum })}
$$

$$
\text { Purelin }(\text { sum })=\text { sum }
$$

The output produced by hidden layer becomes an input to output layer. Neurons in the output layer produce the output by the same method as that of neurons in the hidden layer. An error function is carried out based on predicted output and actual output. The commonly used error function the mean squared error (MSE) was employed in this work which is defined as follow:

$$
M S E=\frac{1}{N} \sum\left(Y_{t}-Y_{N}\right)^{2}
$$

$Y_{t}$ is the target output, $Y_{N}$ is the predicted output and $N$ is the number of points. One of the most employed classes of training algorithms for feed-forward neural network (FFNN) is the back-propagation (BP) method. Training of ANN by means of BP algorithm is an iterative optimization process where the MSE is minimized by adjusting the $w$ and $b$ appropriately. There are many variations of BP algorithm for training NNs. During training step the $w$ and $b$ are iterative updated by LM algorithm until the convergence to the certain value is achieved. Different variables may have various magnitudes, and some could be unmerited, but favorable, effect on the monitored quantity. In this research, all inputs and output are normalized within a uniform range $(0-1)$ according to the below equation:

$$
X_{n o r m}=\frac{\left(X-X_{\min }\right)}{\left(X_{\max }-X_{\min }\right)}
$$

where $X$ is variable, $X_{\max }$ is maximum value and $X_{\min }$ is minimum value.

The process of modeling was divided into three stages: training of ANN, validation and testing of the results. For this purpose, three data sets were required, and therefore, available 54 samples were randomly divided into three sets of training, validating and testing data. The experimental data were randomly divided into three sets: 40,7 and 7 of data sets were used as training, validation and testing, respectively (Table 1). The training data were used to compute the network parameters

\section{Results and Discussion}

After synthesis of catalyst, three detection methods were done to characterize $\mathrm{ZnO}-\mathrm{MgAl}$ 
layered double hydroxides. Figure 2 shows FTIR spectrum of $\mathrm{ZnO}-\mathrm{MgAl}$ layered double hydroxides synthesized using co-precipitation method. Peaks under $1000 \mathrm{~cm}^{-1}$ are because of the $\mathrm{M}-\mathrm{O}$ and $\mathrm{M}-\mathrm{O}-\mathrm{M}$ bond vibration and stretching. Naturally peaks in 1381 and 3457 $\mathrm{cm}^{-1}$ are related to the existence of $\mathrm{CO}_{3}{ }^{2-}$ and hydroxyls groups adsorbed to the layers, respectively. Figure 3 shows the scanning electron microscopy images approving Nano scale synthesis of the $\mathrm{ZnO}-\mathrm{MgAl}$ layered double hydroxides. Since the scale of the Nano composite layers are under $100 \mathrm{~nm}$ more area provided for attraction of irradiated photons and therefor photo catalytic performance of photo catalyst enhanced and caused more dye degradation in aqueous solution. The structural characterization of the synthesized LDH was carried out by XRD. Figure 4 illustrates the XRD pattern of the synthesized catalyst showing layer innate of catalyst, but because of the $\mathrm{ZnO}$ decorated with the layers, peaks are so sharp.

\subsection{RSM modeling}

Response surface designs are useful for modeling a curved quadratic surface to continuous factors. A response surface model can pinpoint a minimum or maximum response, if one exists in the factor region. Three distinct values for each factor are necessary to fit a quadratic function, so the standard two-level designs cannot fit curved surfaces. In this technique, the main objective is to optimize the response surface that is influenced by process parameters [45]. RSM also quantifies the relationship between the controllable input parameters and the obtained response surfaces [46]. Box-Behnken design was used in this study for optimization and modeling of photo catalytic degradation [47]. The Box-Behnken design is an alternative to central composite designs. One distinguishing feature of the Box-Behnken design is that there are only three levels per factor [23].

\subsection{RSM modeling and optimization of photo catalytic treatment}

The 4-factor BBD matrix and experimental results obtained for the photo catalytic degradation of MO from aqueous solution are presented in Table 1. Based on the experimental design (Table 1), the response surface model relating the photo catalytic degradation efficiency with independent variables was constructed to fit experimental data. The linear model in terms of code variables that approximated the efficiency of the photo catalytic degradation process may be written as follows:

$Y=73.32+19.372 X_{1}-5.36 X_{2}+4.384 X_{3}+7.912 X_{4}$ - 8.37X $X_{1}-4.2 X_{2} X_{2}-9.08 X_{3} X_{3}-8.21 X_{4} X_{4}$

$+3.17 X_{1} X_{4}-4.24 X_{2} X_{3}-3.74 X_{2} X_{4}+1.81 X_{3} X_{4}$

where $Y$ is a response variable of dye removal efficiency, $X_{1}$ is calcination temperature $\left({ }^{\circ} \mathrm{C}\right)$,

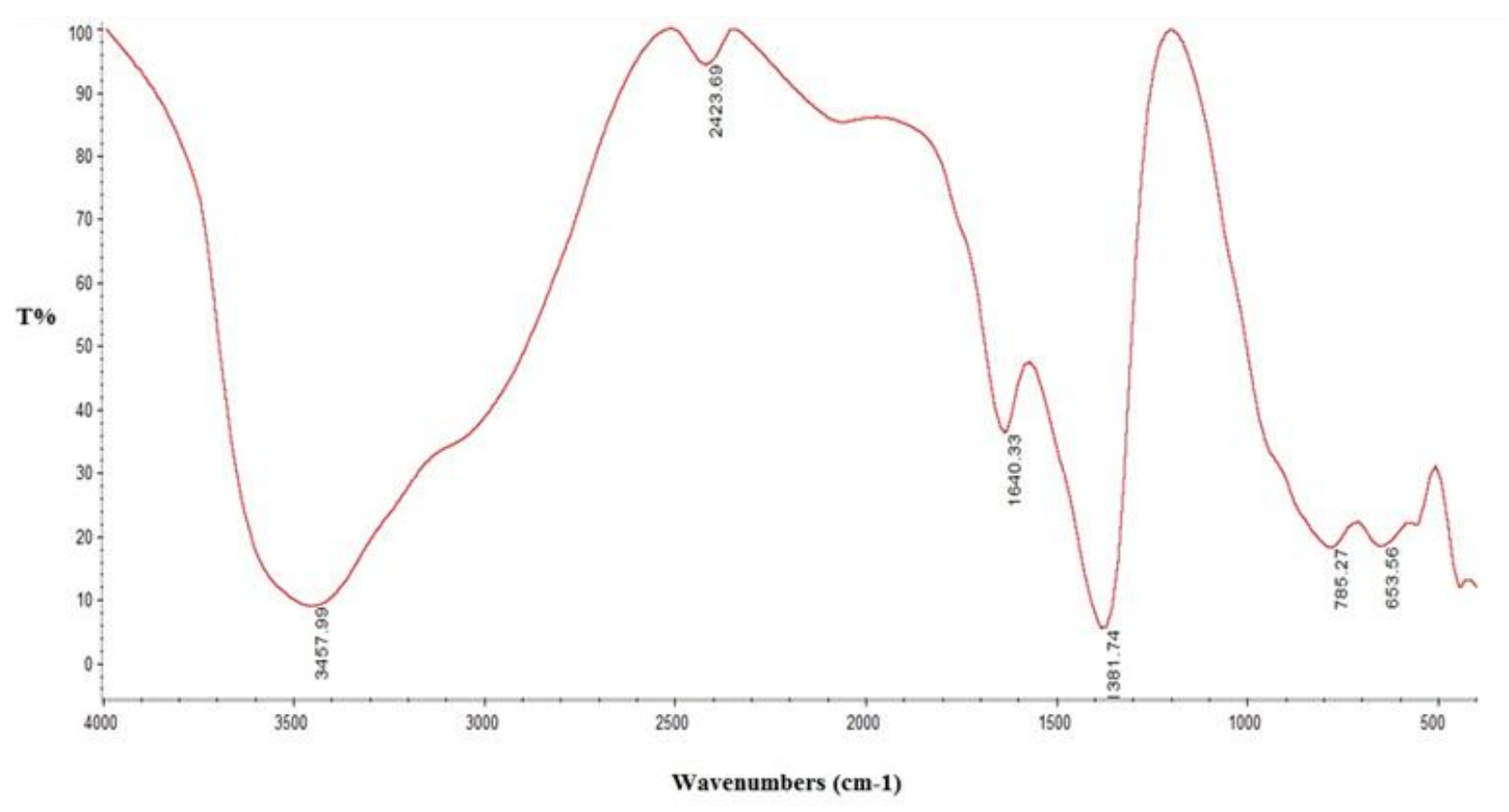

Figure 2. FTIR spectra of $\mathrm{ZnO}-\mathrm{MgAl}$ layered double hydroxide 


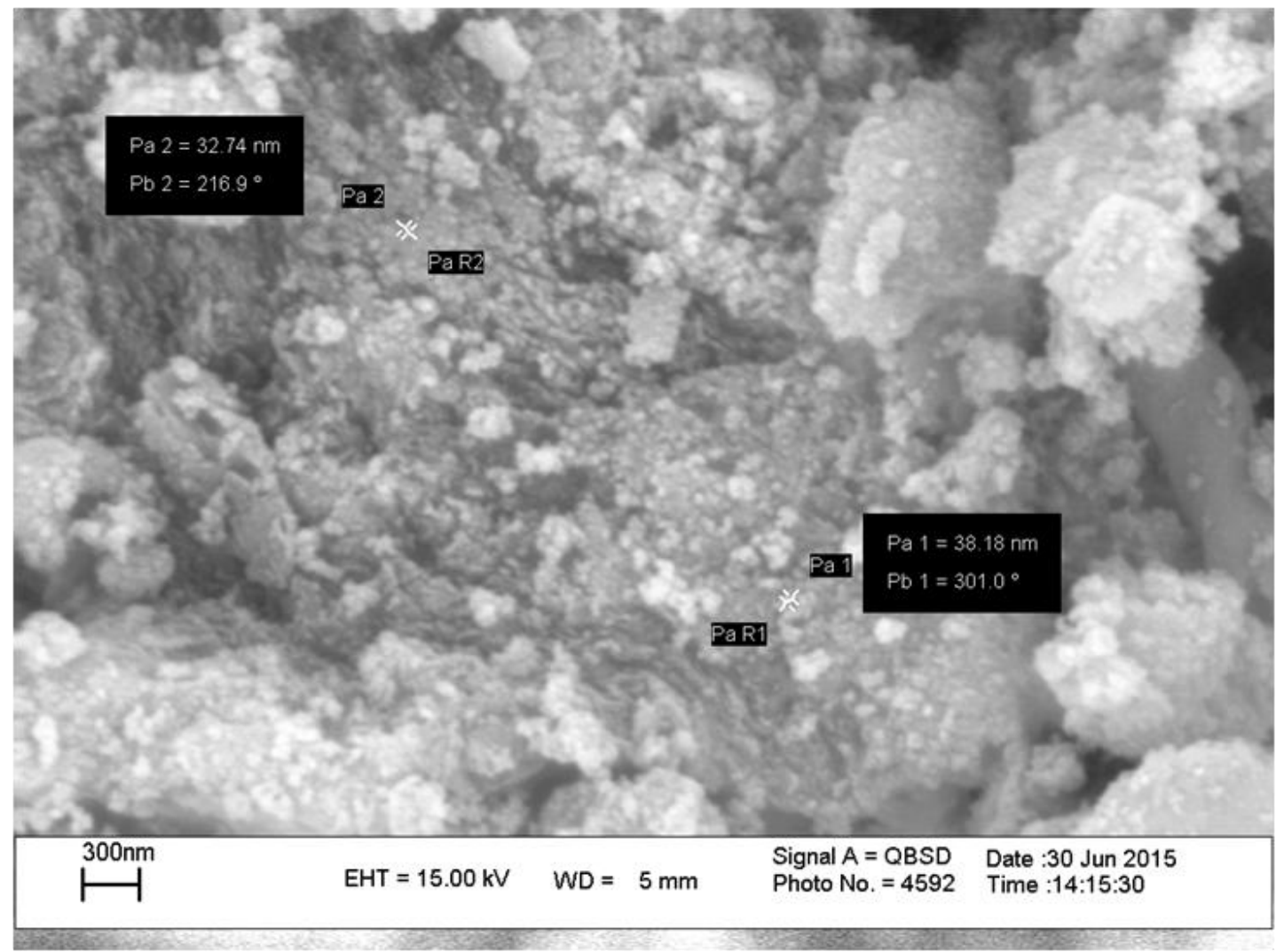

Figure 3. SEM images of surface of the $\mathrm{ZnO}-\mathrm{MgAl}$ layered double hydroxide

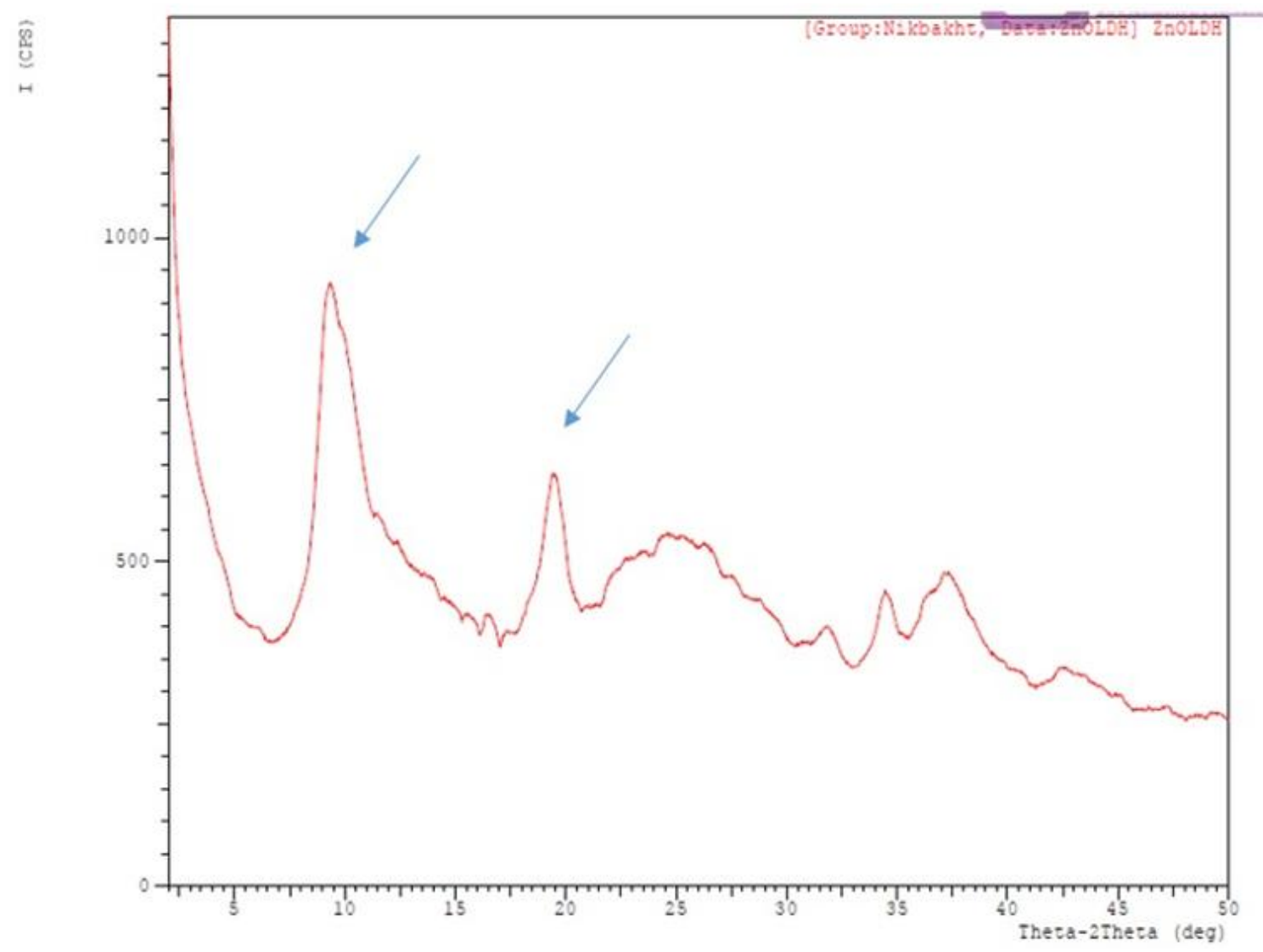

Figure 4. XRD spectrum of $\mathrm{ZnO}-\mathrm{MgAl}$ layered double hydroxides 
$X_{2}=$ dye concentration (ppm), $X_{3}=$ catalyst amount $(\mathrm{mg})$, and $X_{4}=$ irradiation time ( $\left.\mathrm{min}\right)$. Meanwhile, the $b_{i}$ are regression coefficients for linear effects; $b_{i i}$ the regression coefficients for squared effects; $b_{i k}$ the regression coefficients for interaction effects and $x_{i}$ are coded experimental levels of the variables. The model explained perfectly the experimental range studied, as can be seen from a comparison of the graphical representation of actual vs. predicted values (Figure 5).

Table 2 shows the results of the ANOVA analysis of the linear model for the photo catalytic oxidation of dye wastewater. Larger $F$ values and smaller $P$ values are an indication of the significance of the model. The model $F$ value of 53.32 and $P$ value $<0.0001$ implied the high significance of the model. There was only a $0.01 \%$ chance that the 'Model $F$ value' could occur due to noise. $P$ values less than 0.05 indicated which model terms are significant. In this case, all the factors were highly significant because $P<0.05$. The 'Lack of Fit $F$ value' of 2.58 and $P$ value of 0.018 implied that the lack of fit was not significant relative to the pure error. The non-significant lack-of-fit indicated good predictability of the model. Coefficient of determination $\left(R^{2}\right)$ is defined as the ratio of the explained variable to the total variation and a measure of the degree of fit. It was found that the predicted values matched the experimental values reasonably well with $\mathrm{R}^{2}=0.9407$. This implied that $94.07 \%$ of the variations for $\mathrm{MO}$ removal were explained by the independent variables and this also meant that the model did not explain only $5.93 \%$ of the variation. The $\mathrm{R}^{2}$ of 0.9407 was in reasonable agreement with Adj.R ${ }^{2}$ of 0.9222 , also indicating better predictability of the model (Table 3).

The student $t$ distribution and the corresponding values, along with the parameter estimate, are given in Table 4. The $P$-values were used as a tool to check the significance of each coefficient, which, in turn, are necessary to understand the pattern of the mutual interactions between the test variables. The larger the magnitude of the $t$-value and smaller the $P$-value, the more significant is the corresponding coefficient.

\subsection{Response surface and contour plots for MO removal of the aqueous solution}

Three dimensional response surface plots and counter plots computed by means of the response surface model for dye removal from wastewaters are shown in Figures 6-8, revealing the predicted effects of factors upon response.

Figure 6 illustrates the effect of calcination temperature and the irradiation time on dye removal efficiency (CR \%) for initial dye con-

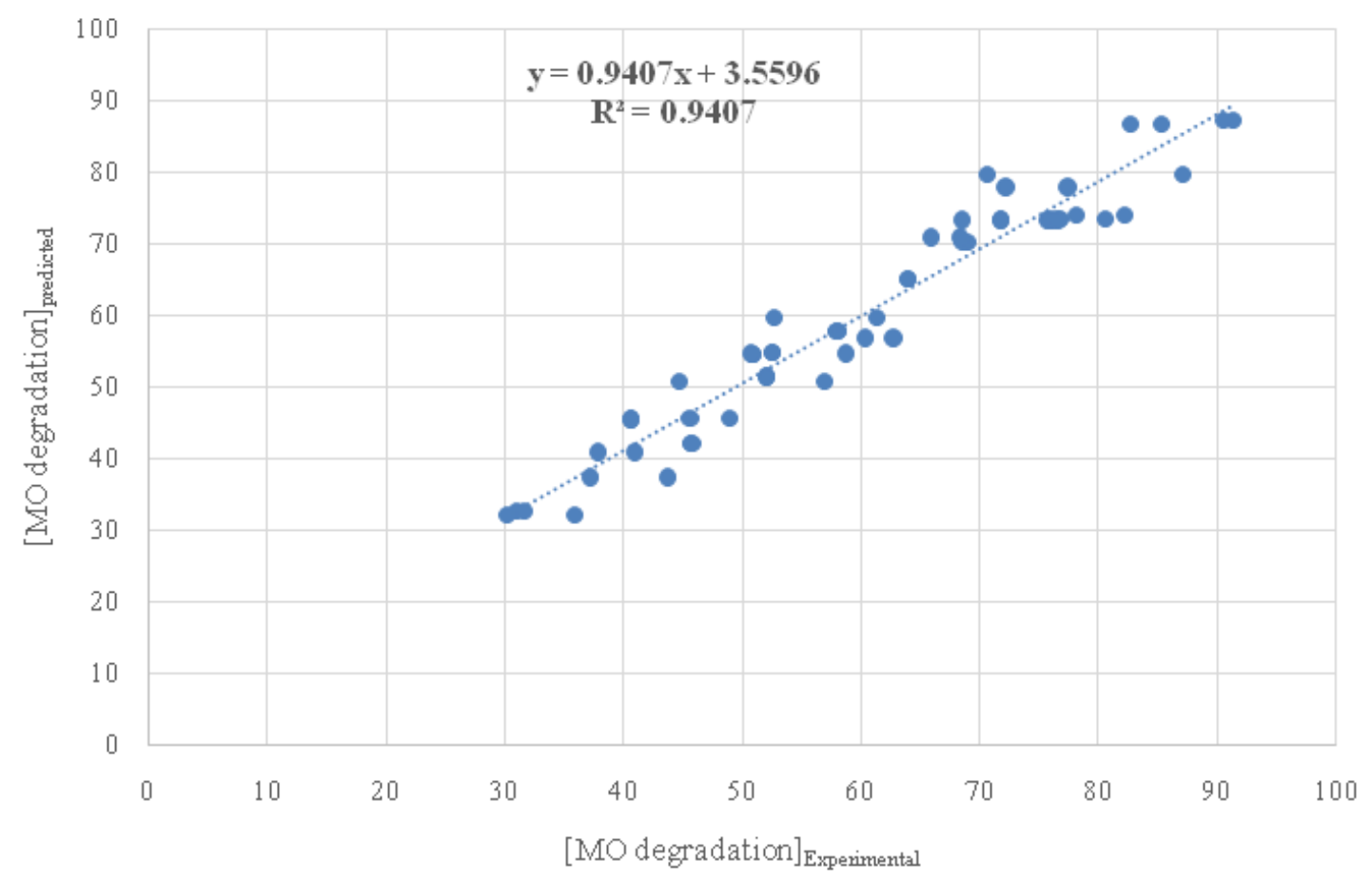

Figure 5. Comparison of the experimental results of MO degradation efficiency (CR \%) with those calculated via Box-Behnken design resulted equation 
centration. It is observed in Figure 6 that the removal efficiency, increased with increasing both calcination temperature and irradiation time and at least more than 94\% dye removal was obtained after $600{ }^{\circ} \mathrm{C}$ calcination and 120 minute UV irradiation. It is also obvious that both of these two Independent variables are so important in dye removal. Since photo catalyst was synthesized in nano scale structure by drop wise addition of the two solutions, area is greater than the volume and cause more photon attraction on the surface of the photo catalyst and eventually more degradation of the organic pollutant by photocatalytic process. So it's obvious that drop wise addition of the cations solution on the caustic solution is so important because of the Nanostructure synthesis of photo catalyst-adsorbent.
Figure 7 illustrates the effect of calcination temperature and catalyst amount on dye removal efficiency (CR \%). As it is obvious, by adding more amount of catalyst, more electronhole $\left(\mathrm{e}-\mathrm{h}^{+}\right)$pairs have been created and caused more MO removal from the aqueous solution that led to enhancement in dye removal. Whereas the increasing amount of photo catalyst that decorated on $\mathrm{MgAl}$ layered double hydroxide, increase more space for adsorption of organic dye pollutant that finally can be degrade by $\mathrm{ZnO}$ decorated on the adsorbent. So both of the calcination temperature and amount of photo catalyst enhance the performance of the synthesized material.

Figure 8 illustrates the effect of irradiation time and catalyst amount on MO removal (CR \%). It shows that prolonging the time of UV ir-

Table 2. Analysis of variance (ANOVA) for fit of MO removal efficiency from Box-Behnken design

\begin{tabular}{cccccc}
\hline $\begin{array}{c}\text { Source of } \\
\text { variations }\end{array}$ & $\begin{array}{c}\text { Sum of } \\
\text { square }\end{array}$ & $\begin{array}{c}\text { Degree of free- } \\
\text { dom }\end{array}$ & $\begin{array}{c}\text { Adjusted mean } \\
\text { square }\end{array}$ & $F$-value & $P$-value \\
\hline Regression & 13445.7 & 12 & 1120.48 & 53.32 & 0.000 \\
Lack of fit & 444.6 & 12 & 37.05 & 2.58 & 0.018 \\
Residuals & 861.6 & 41 & 21.01 & - & - \\
\hline Total & 14307.3 & 52 & - & - & - \\
\hline
\end{tabular}

Table 3. Statistical measures and performance of the RSM using Analysis of variance (ANOVA)

\begin{tabular}{cccc}
\hline $\mathrm{S}$ & $\mathrm{R}^{2}$ & $\mathrm{R}^{2}(\mathrm{adj})$ & $\mathrm{R}^{2}$ (pred) \\
\hline 4.58405 & $94.07 \%$ & $92.22 \%$ & $89.65 \%$ \\
\hline
\end{tabular}

Table 4. Estimated regression coefficients and corresponding $t$ and $P$-values from the data of BoxBehnken design experiments

\begin{tabular}{ccccc}
\hline Coefficient & Parameter estimate & Standard Error & $t$-value & $P$-value \\
\hline b0 & 73.32 & 1.89 & 38.84 & 0 \\
b1 & 19.372 & 0.944 & 20.53 & 0 \\
b2 & -5.36 & 0.944 & -5.68 & 0 \\
b3 & 4.384 & 0.944 & 4.65 & 0 \\
b4 & 7.912 & 0.944 & 8.38 & 0 \\
b11 & -8.37 & 1.42 & -5.91 & 0 \\
b22 & -4.2 & 1.42 & -2.96 & 0.05 \\
b33 & -9.08 & 1.42 & -6.41 & 0 \\
b44 & -8.21 & 1.42 & -5.8 & 0 \\
b14 & 3.17 & 1.63 & 1.94 & 0.06 \\
b23 & -4.24 & 1.63 & -2.6 & 0.013 \\
b24 & -3.74 & 1.63 & -2.29 & 0.028 \\
b34 & 1.81 & 1.63 & 1.11 & 0.274 \\
\hline
\end{tabular}


radiation, cause more dye removal because of more $\mathrm{e}-\mathrm{h}^{+}$pairs created and finally the dye degradation performance increased.

\subsection{Determination of optimal conditions for MO removal}

The desired goal in term of dye removal efficiency was defined as "maximize" to achieve highest treatment performance. The optimum values of the process variables in optimum conditions are $600\left({ }^{\circ} \mathrm{C}\right), 20(\mathrm{ppm}), 0.05(\mathrm{mg})$ and 120 (min) calcination temperature, dye concentration, catalyst amount and irradiation time, respectively. After verification through a further experimental test with the predicted values, the result indicates that the maximum dye removal efficiency was obtained when the values of each parameter were set as the optimum values. It implies that the strategy to optimize the removal conditions and to obtain the maximal removal efficiency by RSM for the photo catalytic removal of the $\mathrm{MO}$ with $\mathrm{ZnO}-\mathrm{MgAl}$ layered double hydroxide was effective.

\subsection{ANN modeling}

Artificial neural networks (ANN's) are inspired by biological neural systems. In this approach weighted sum of inputs arriving at each neuron is passed through an activation function (generally nonlinear) to generate an output signal [48]. An additional bias input is added to the weighted sum for increasing or lowering the net input to the activation function. Functions thus synthesized are largely determined by the network architecture and connections between the processing units [49]. Majority of ANN architectures are feedforward networks which are mostly trained from the input data using error backpropagation algorithm. Each input node represents an independent variable while the output nodes give the dependent variables.
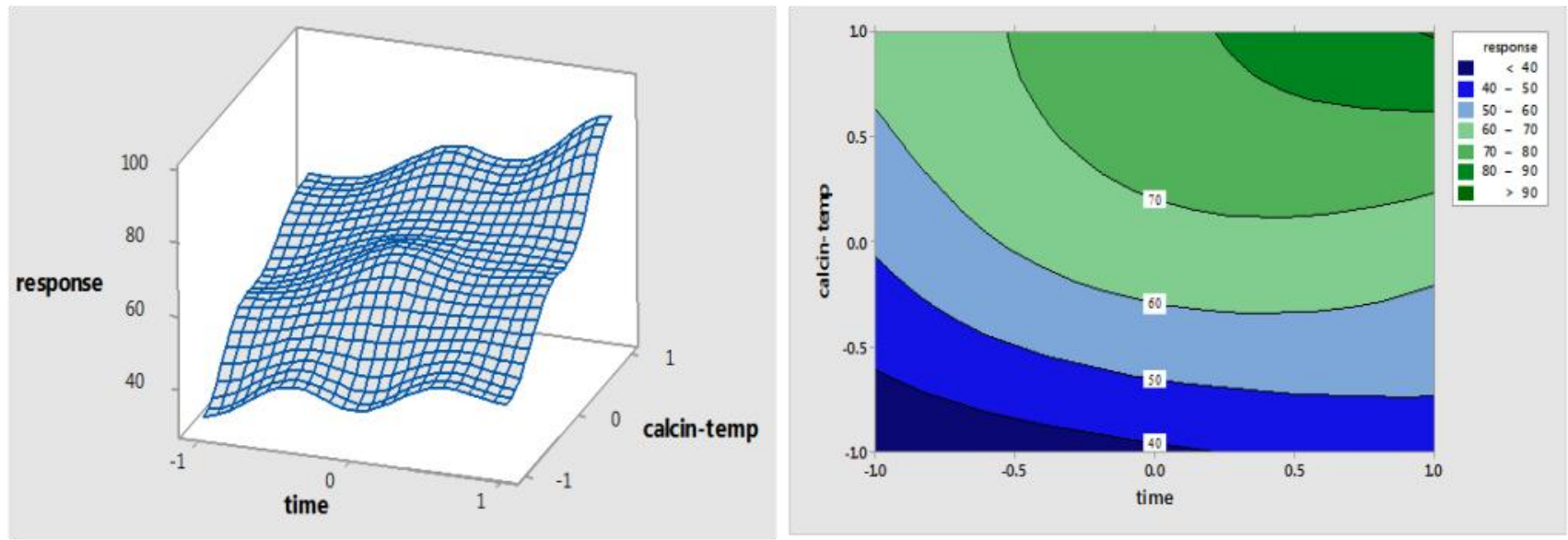

Figure 6. The response surface plot and contour plot for MO removal efficiency (CR \%) as the function of calcination temperature $\left({ }^{\circ} \mathrm{C}\right)$ and UV lamp irradiation time (min).
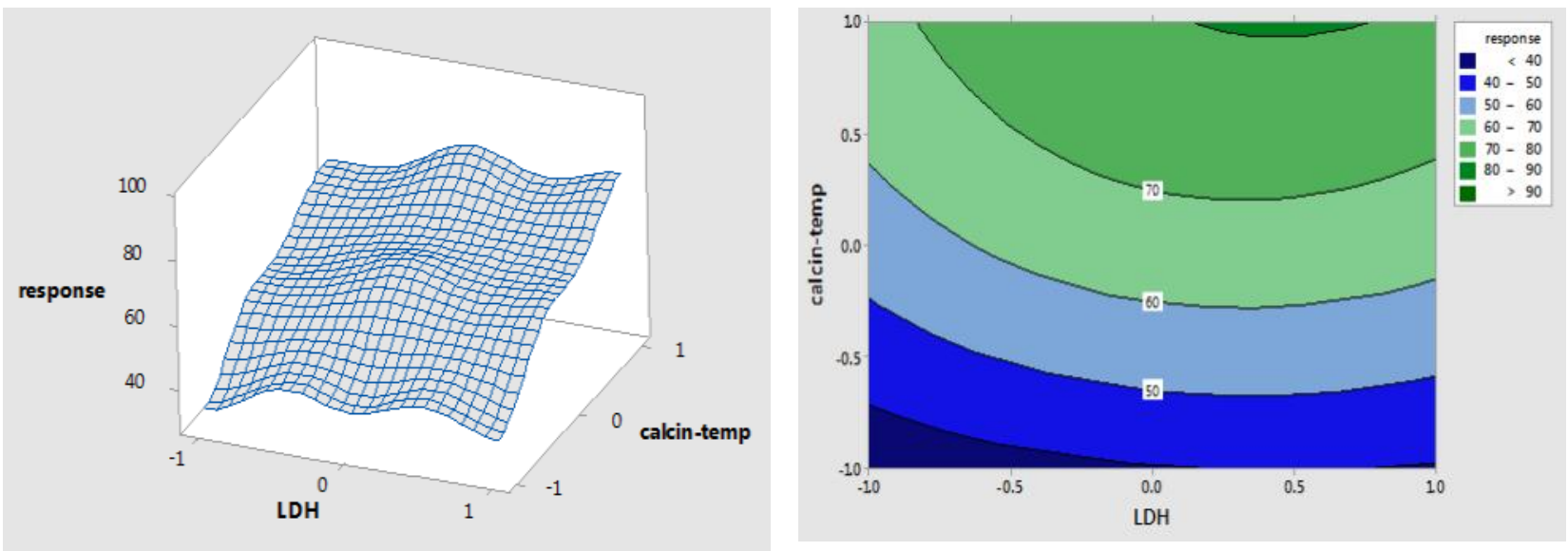

Figure 7. the response surface plot and contour plot of the dye removal efficiency (CR \%) as the function of calcination temperature $\left({ }^{\circ} \mathrm{C}\right)$ and catalyst amount $(\mathrm{mg})$. 
Hidden layers are employed to perform nonlinear transformations on the input space and are used for computation purpose [28]. ANN modeling Network topology has important influences on the predicted results. The number of input and output neurons is equal to the number of input and output data, respectively. However, the number of neurons in hidden layer was recognized by training several ANN topologies and selecting the optimal one based on minimization of MSE and improving generalization ability of the topology [46]. In this study, the optimal topology of the ANN model was including four inputs, one hidden layer with 5 neurons and one output layer [32].

A fully connected three-layer feed-forward network with the input, hidden, and output layers is shown in Figure 9. Each node in the input layer represents the value of one independent variable while the output nodes indicate the dependent variables. Selection of optimum number of hidden layer neurons in the ANN architecture falls in the rubric of biasvariance dilemma. Bias indicates the degree of agreement between the model and the training data whereas variance represents the complexity of the approximating model. The number of hidden neurons determines the model complexity of an ANN. Increase in the number of hidden layer neurons compromises the generalization ability of the ANN at the cost of minimizing the training data set error.

In order to determine the optimal number of neurons in the hidden layer, MLPs with different number of hidden layer neurons (varying from 1-30 in our case) were trained. The optimal networks found were afterwards used to identify the optimum regions on the basis of the maximum photo catalytic oxidation

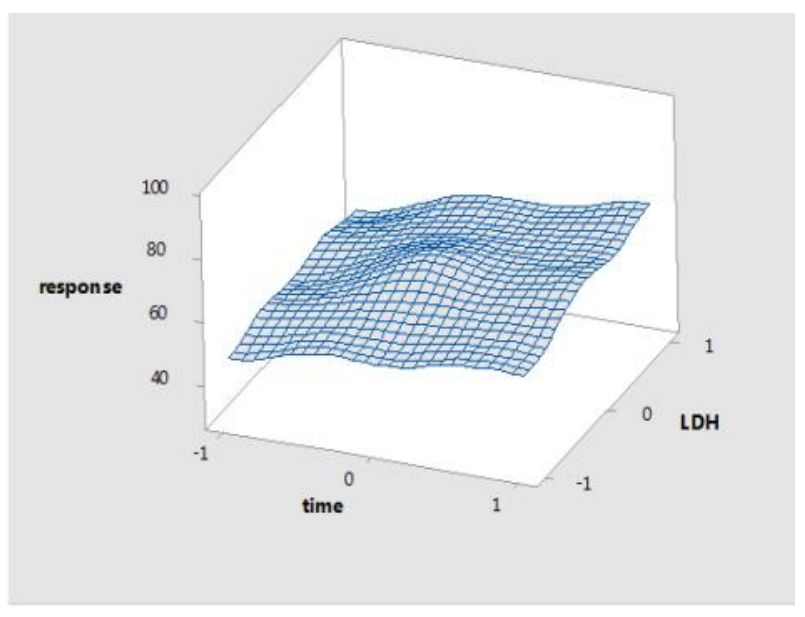

rate of MO and eventually 5 neuron was selected as the best for modeling process (Figure 10).

The degradation of MO as organic pollutant, as predicted by the ANN is compared to the experimentally obtained values in Figure 11 In order to test the suitability of the model, the predicted and actual results were plotted in Figure 11 and the coefficient of determination $\left(\mathrm{R}^{2}=0.968\right)$ illustrates good agreement with the two sets of results.

The determination coefficient $\left(\mathrm{R}^{2}\right)$ for training, validation, testing and all data sets are summarized and presented in Table 5 proving the good proximity of the designed model for MO removal from aqueous solution. The Table 6 shows the statistical analysis of the experimental data versus predicted data of artificial neural network model. The ability of the model in prediction of varying data is clearly observable in high percentage of the $\mathrm{R}^{2}$ and $\mathrm{R}^{2}$ (adj). The analysis of ANOVA for ANN model with their $\mathrm{F}$ and $\mathrm{P}$-values are listed in Table 7 and accepting the capability of the model and advantage of the artificial neural network in predicting the process rather than response surface methodology. In order to analyze graphically the effect of the each factors in degradation of methyl orange Figure 12 is designated by authors.

The RSM and ANN models constructed out of the experimental data correlated fairly well $\left(\mathrm{R}^{2}=0.9407\right.$ for response surface methodology and $\mathrm{R}^{2}=0.968$ for artificial neural network). Further two validation experiments were performed and the response of both the models was found in agreement with the experimental results. The main effects model indicated that calcination temperature has highest positive effect on MO removal efficiency as observed

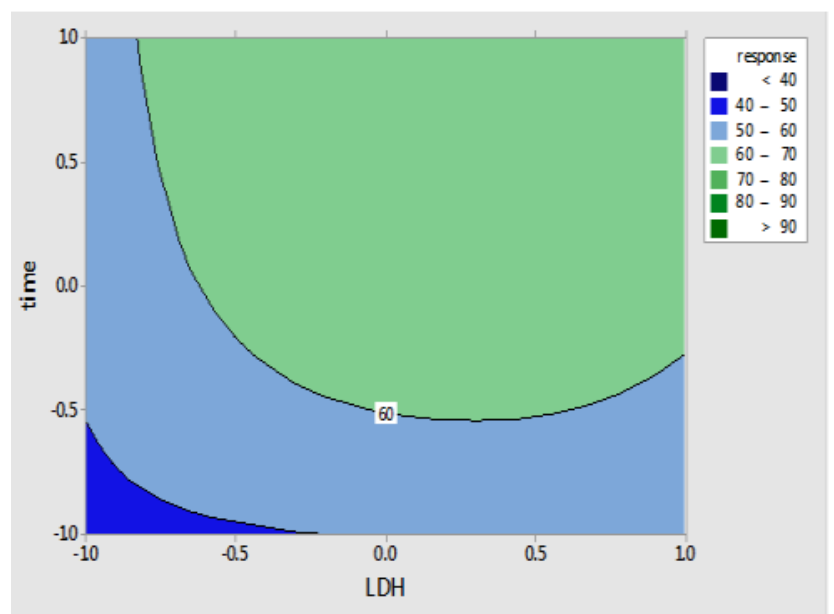

Figure 8. the response surface plot and contour plot of the dye removal (CR \%) as the function of the irradiation time (min) and catalyst amount $(\mathrm{mg})$ 


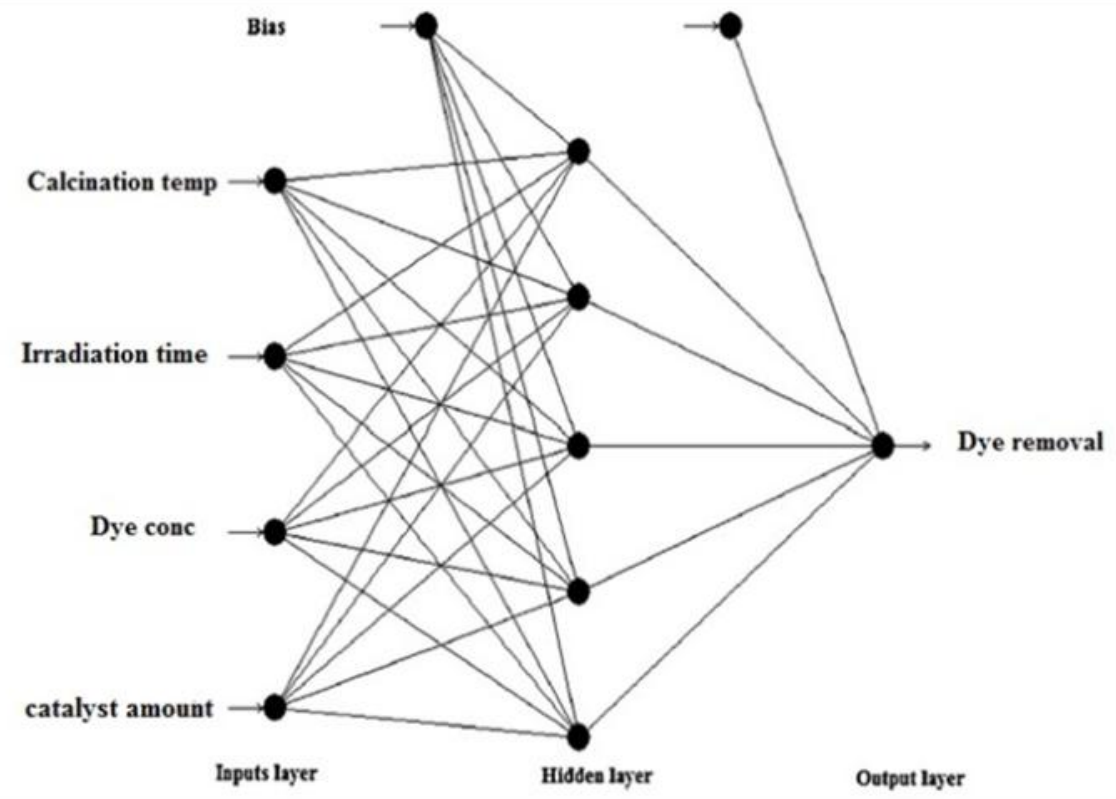

Figure 9. Schematic of the ANN architecture used in this study

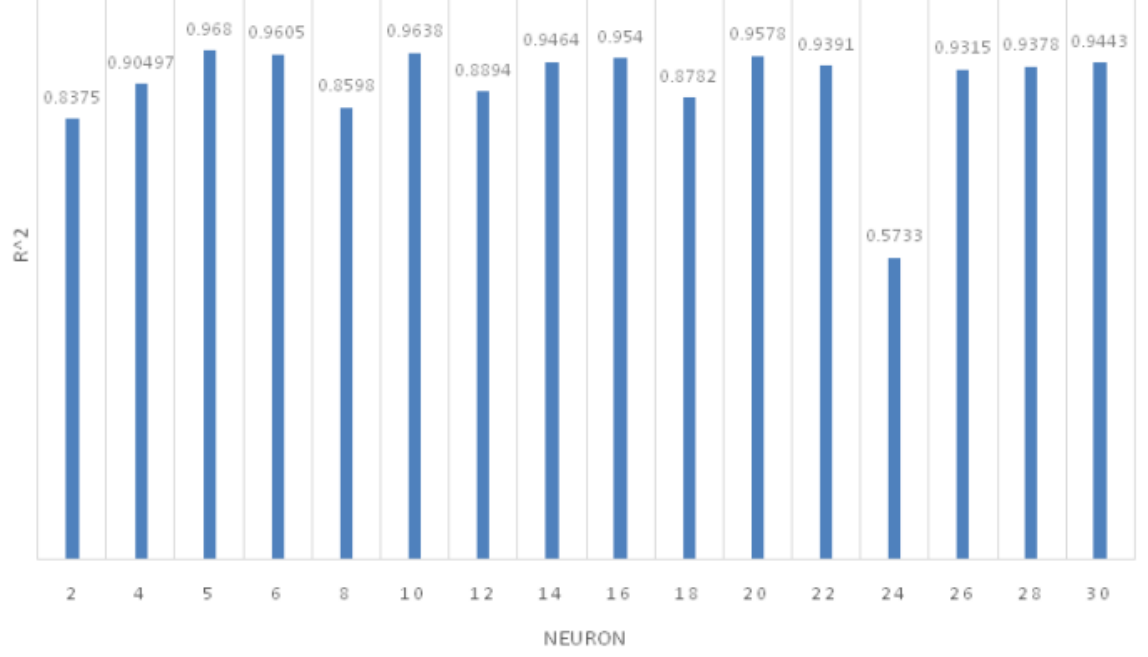

Figure 10. Effect of the number of the neuron in hidden layer

Table 5. Statistical measures and performance of the ANN model for training, testing, validation and all data

\begin{tabular}{cccc}
\hline \multicolumn{4}{c}{$\mathrm{R}^{2}$} \\
\hline training & validation & testing & all \\
0.98274 & 0.99148 & 0.97801 & 0.98389 \\
\hline
\end{tabular}

Table 6. Statistical measures and performance of the ANN using Analysis of variance (ANOVA)

\begin{tabular}{ccc}
\hline $\mathrm{S}$ & $\mathrm{R}^{2}$ & $\mathrm{R}^{2}(\mathrm{adj})$ \\
\hline 0.0394223 & $96.8 \%$ & $96.7 \%$ \\
\hline
\end{tabular}

Table 7. Analysis of variance (ANOVA) for fit of MO removal efficiency from LM-algorithm by artificial neural network

\begin{tabular}{cccccc}
\hline Source & Degree of freedom & Adj SS & Adj MS & $F$-value & $P$-value \\
\hline Regression & 1 & 2.44696 & 2.44696 & 1574.50 & 0 \\
Error & 52 & 0.08081 & 0.00155 & & \\
\hline Total & 53 & 2.52778 & & & \\
\hline
\end{tabular}


through beta regression coefficients, whereas, photo catalyst amount and treatment time have less positive effects on MO removal efficiency. Response surface and contour plots for calcination temperature and treatment time (Figure 6), and calcination temperature and photo catalyst amount (Figure 7) have strong interactions for MO removal efficiency. All three calcination temperature, photo catalyst amount and irradiation time, increase the dye removal efficiency, but the calcination temperature has higher contribution as observed from beta regression coefficients, than the photo catalyst amount and irradiation time. Energy conservation in the process can be better achieved by increasing the treatment time, and reducing the amount of photo catalyst. But, this will ultimately increase the reactor size.

\section{Conclusions}

$\mathrm{ZnO}-\mathrm{MgAl}$ layered double hydroxides exhibited promising photo catalytic activity in the removal of MO from dye wastewaters. The design experiments and the study the interaction between factors were successfully carried out by response surface methodology and the modeling was done by artificial neural network. Response surface plots provide a good way for visualizing the parameter interactions

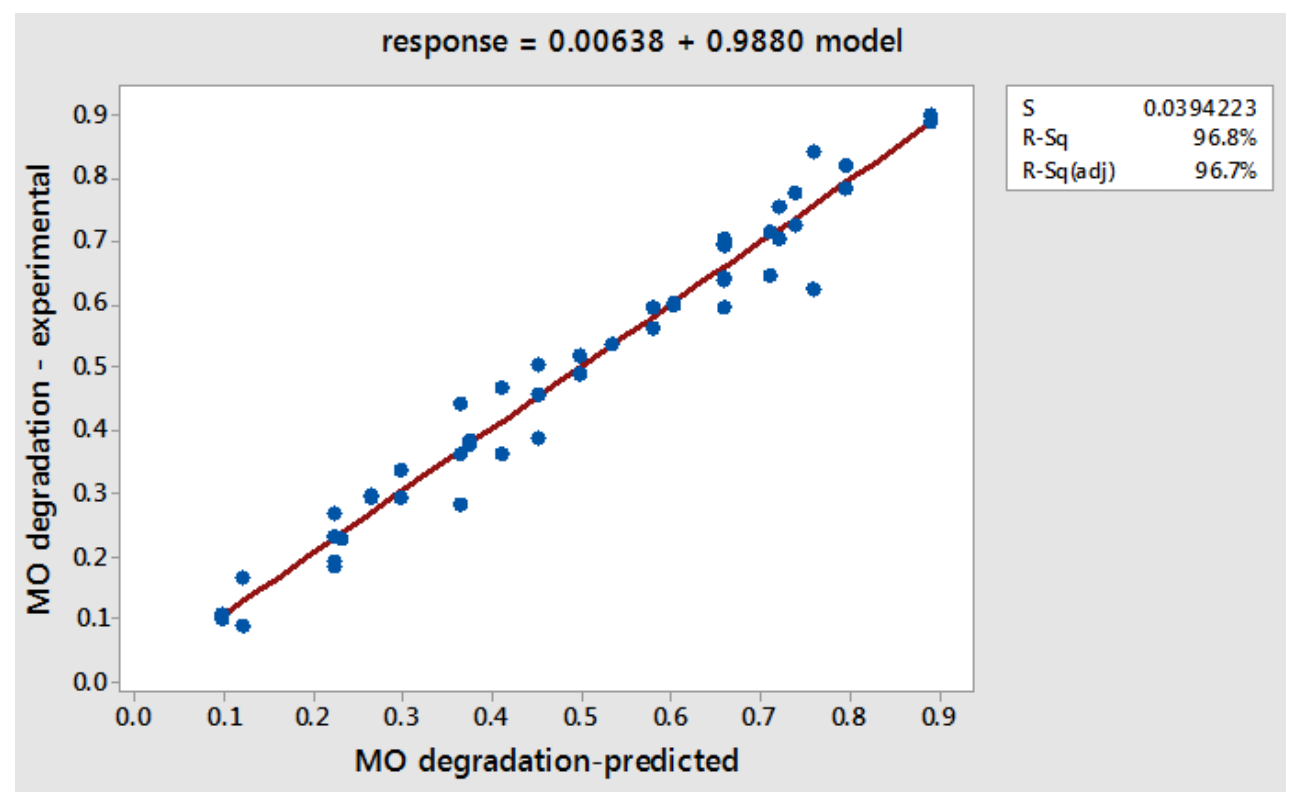

Figure 11. Scatter plot of the ANN predicted versus actual of lead ions removal

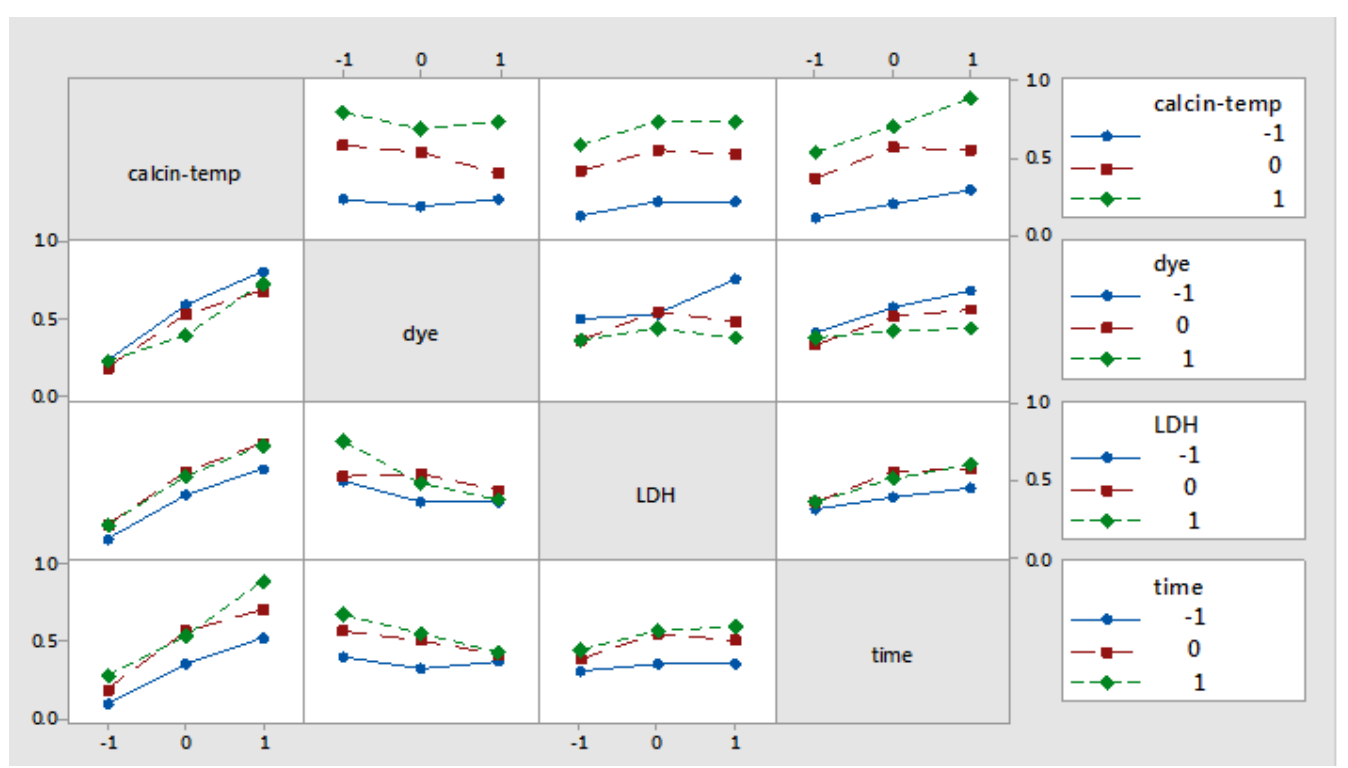

Figure12. The graphical interactions of the factors together 
and the resulting model for photo catalytic removal process explained $94.07 \%$ variance $\left(\mathrm{R}^{2}\right.$ $=0.9407)$ for dye removal efficiency. The plots indicate that the best conditions for dye removal was $600{ }^{\circ} \mathrm{C}, 120 \mathrm{~min}, 0.05 \mathrm{~g}$ for calcination temperature, irradiation time and catalyst amount, respectively. The ANN model developed from the limited experimental data scored fairly well on the validation experiments, indicating that this model was able to capture the nonlinearities of the experimental data better than the RSM model with a combined regression coefficient of 0.968 for MO photo catalytic removal efficiency.

\section{Acknowledgement}

This article resulted from research project No 94.S.006 funded by deputy of research, Urmia University, Urmia, Iran.

\section{References}

[1] LeMire, G.J., HeinigJr, C.F., LeMire, E.A. (1985) System and method for water purification. U.S. Patent Number 4504387 A.

[2] Al-Rasheed, R.A. (2005). Water treatment by heterogeneous photocatalysis an overview. In 4th SWCC acquired Experience Symposium held in Jedda.

[3] Byrne, J.A., Fernandez-Ibanez, P.A., Dunlop, P.S., Alrousan, D., Hamilton, J.W. (2011). Photocatalytic enhancement for solar disinfection of water: a review. Int. J. Photoeng., 2011: 1-12.

[4] Antonopoulou, M., Konstantinou, I. (2013). Optimization and Modeling of the Photocatalytic Degradation of the Insect Repellent DEET in Aqueous $\mathrm{TiO}_{2}$ Suspensions. CLEAN - Soil, Air, Water, 41: 593-600.

[5] Zhao, J., Yang, X. (2003). Photocatalytic oxidation for indoor air purification: a literature review. Building and Environment, 38: 645654.

[6] Mozia, S., Tomaszewska, M., Morawski, A.W. (2005). Photocatalytic degradation of azo-dye Acid Red 18. Desalination, 185: 449-456.

[7] Kitsiou, V., Filippidis, N., Mantzavinos, D., Poulios, I. (2009). Heterogeneous and homogeneous photocatalytic degradation of the insecticide imidacloprid in aqueous solutions. $A p$ plied Catalysis B: Environmental, 86: 27-35.

[8] Bubacz, K., Kusiak-Nejman, E., Tryba, B., Morawski, A.W. (2013). Investigation of $\mathrm{OH}$ radicals formation on the surface of $\mathrm{TiO}_{2} / \mathrm{N}$ photocatalyst at the presence of terephthalic acid solution. Estimation of optimal conditions. Journal of Photochemistry and Photobiology A: Chemistry, 261: 7-11.
[9] Jiang, W., Joens, J.A., Dionysiou, D.D., O'Shea, K.E. (2013). Optimization of photocatalytic performance of $\mathrm{TiO}_{2}$ coated glass microspheres using response surface methodology and the application for degradation of dimethyl phthalate. Journal of Photochemistry and Photobiology A: Chemistry, 262: 7-13.

[10] Saien, J., Soleymani, A.R., Bayat, H. (2012). Modeling Fentonic advanced oxidation process decolorization of Direct Red 16 using artificial neural network technique. Desalination and Water Treatment, 40: 174-182.

[11] Daraei, H., Maleki, A., Mahvi, A.H., Zandsalimi, Y., Alaei, L., Gharibi, F. (2014). Synthesis of $\mathrm{ZnO}$ nano-sono-catalyst for degradation of reactive dye focusing on energy consumption: operational parameters influence, modeling, and optimization. Desalination and Water Treatment, 52: 6745-6755.

[12] Yang, L., Fan, B., Cui, X., Shi, X., Li, R. (2015). Solvent-free aerobic oxidation of ethylbenzene over Mn-containing silylated $\mathrm{MgAl}$ layered double hydroxides. Journal of Industrial and Engineering Chemistry, 21: 689-695.

[13] Sun, X., Imai, T., Sekine, M., Higuchi, T., Yamamoto, K., Kanno, A., Nakazono, S. (2014). Adsorption of phosphate using calcined $\mathrm{Mg}_{3}$ Fe layered double hydroxides in a fixed-bed column study. Journal of Industrial and Engineering Chemistry, 20: 3623-3630.

[14] Andreozzi, R., Caprio, V., Insola, A., Marotta, R. (1999). Advanced oxidation processes (AOP) for water purification and recovery. Catalysis Today, 53: 51-59.

[15] Shan, R.-r., Yan, L.-g., Yang, Y.-m., Yang, K., Yu, S.-j., Yu, H.-q., Zhu, B.-c., Du, B. (2015). Highly efficient removal of three red dyes by adsorption onto $\mathrm{Mg}$-Al-layered double hydroxide. Journal of Industrial and Engineering Chemistry, 21: 561-568.

[16] Nitoi, I., Oancea, P., Raileanu, M., Crisan, M., Constantin, L., Cristea, I. (2015). UV-VIS photocatalytic degradation of nitrobenzene from water using heavy metal doped titania. Journal of Industrial and Engineering Chemistry, 21: 677-682.

[17] Nezamzadeh-Ejhieh, A., KhodabakhshiChermahini, F. (2014). Incorporated $\mathrm{ZnO}$ onto nano clinoptilolite particles as the active centers in the photodegradation of phenylhydrazine. Journal of Industrial and Engineering Chemistry, 20: 695-704.

[18] Cho, I.-H., Zoh, K.-D. (2007). Photocatalytic degradation of azo dye (Reactive Red 120) in $\mathrm{TiO}_{2 /} \mathrm{UV}$ system: Optimization and modeling using a response surface methodology (RSM) based on the central composite design. Dyes and Pigments, 75: 533-543. 
[19] Ayodele, B.V., Cheng, C.K. (2015). Modelling and optimization of syngas production from methane dry reforming over ceria-supported cobalt catalyst using artificial neural networks and Box-Behnken design. Journal of Industrial and Engineering Chemistry, 32: 246-258.

[20] Badrnezhad, R., Mirza, B. (2014). Modeling and optimization of cross-flow ultrafiltration using hybrid neural network-genetic algorithm approach. Journal of Industrial and Engineering Chemistry, 20: 528-543.

[21] Shabanzadeh, P., Yusof, R., Shameli, K. (2015). Artificial neural network for modeling the size of silver nanoparticles' prepared in montmorillonite/starch bionanocomposites. Journal of Industrial and Engineering Chemistry, 24: 42-50.

[22] Khajeh, M., Kaykhaii, M., Sharafi, A. (2013). Application of PSO-artificial neural network and response surface methodology for removal of methylene blue using silver nanoparticles from water samples. Journal of Industrial and Engineering Chemistry, 19: 1624-1630.

[23] Shojaeimehr, T., Rahimpour, F., Khadivi, M.A., Sadeghi, M. (2014). A modeling study by response surface methodology (RSM) and artificial neural network (ANN) on $\mathrm{Cu}^{2+}$ adsorption optimization using light expended clay aggregate (LECA). Journal of Industrial and Engineering Chemistry, 20: 870-880.

[24] Istadi, I., Anggoro, D.D., Buchori, L., Utami, I., Solikhah, R. (2012). Process parameters optimization of potential $\mathrm{SO}_{4}^{2-/ Z n O}$ acid catalyst for heterogeneous transesterification of vegetable oil to biodiesel. Bulletin of Chemical Reaction Engineering and Catalysis, 7 (2): 150-157.

[25] Istadi, I., Amin, N.A.S. (2005). A hybrid numerical approach for multi-responses optimization of process parameters and catalyst compositions in $\mathrm{CO}_{2} \mathrm{OCM}$ process over $\mathrm{CaO}$ $\mathrm{MnO} / \mathrm{CeO}_{2}$ catalyst. Chemical Engineering Journal, 106(3): 213-227.

[26] Hafizi, A., Ahmadpour, A., Koolivand-Salooki, M., Heravi, M.M., Bamoharram, F.F. (2013). Comparison of RSM and ANN for the investigation of linear alkylbenzene synthesis over $\mathrm{H}_{14}\left[\mathrm{NaP}_{5} \mathrm{~W}_{30} \mathrm{O}_{110}\right] / \mathrm{SiO}_{2}$ catalyst. Journal of Industrial and Engineering Chemistry, 19: 1981-1989.

[27] Khataee, A.R., Zarei, M., Moradkhannejhad, L. (2010). Application of response surface methodology for optimization of azo dye removal by oxalate catalyzed photoelectroFenton process using carbon nanotube-PTFE cathode. Desalination, 258: 112-119.

[28] Myers, R.H., Montgomery, D.C., Vining, G.G., Borror, C.M., Kowalski, S.M. (2004). Re- sponse surface methodology: a retrospective and literature survey. Journal of Quality Technology, 36: 53.

[29] Khataee, A.R., Zarei, M., Moradkhannejhad, L. (2010). Application of response surface methodology for optimization of azo dye removal by oxalate catalyzed photoelectroFenton process using carbon nanotube-PTFE cathode. Desalination, 258:112-119.

[30] Bezerra, M.A., Santelli, R.E., Oliveira, E.P., Villar, L.S., Escaleira, L.A. (2008). Response surface methodology (RSM) as a tool for optimization in analytical chemistry. Talanta, 76: 965-977.

[31] Shao, P., Jiang, S., Ying, Y. (2007). Optimization of molecular distillation for recovery of tocopherol from rapeseed oil deodorizer distillate using response surface and artificial neural network models. Food and Bioproducts Processing, 85: 85-92.

[32] Kempthorne, O. (1952) The design and analysis of experiments, NewYork, John Wiley and Sons Inc.

[33] Corma, A., Serra, J.M., Serna, P., Valero, S., Argente, E., Botti, V. (2005). Optimisation of olefin epoxidation catalysts with the application of high-throughput and genetic algorithms assisted by artificial neural networks (softcomputing techniques). Journal of $\mathrm{Ca}$ talysis, 229: 513-524.

[34] Bas, D., Boyaci, I.H. (2007). Modeling and optimization II: comparison of estimation capabilities of response surface methodology with artificial neural networks in a biochemical reaction. Journal of Food Engineering, 78: 846854.

[35] Huitao, L., Ketai, W., Hongping, X., Xingguo, C., Zhide, H. (2002). Application of experimental design and artificial neural networks to separation and determination of active components in traditional Chinese medicinal preparations by capillary electrophoresis. Chromatographia, 55: 579-583.

[36] Frías-García, S., Sánchez, M.J., Rodríguez-Delgado, M.Á. (2004). Optimization of the separation of a group of triazine herbicides by micellar capillary electrophoresis using experimental design and artificial neural networks. Electrophoresis, 25: 10421050 .

[37] Boti, V.I., Sakkas, V.A., Albanis, T.A. (2009). An experimental design approach employing artificial neural networks for the determination of potential endocrine disruptors in food using matrix solid-phase dispersion. Journal of Chromatography A, 1216: 1296-1304.

[38] Papadopoulos, V.D., Beligiannis, G.N., Hela, D.G. (2011). Combining experimental design 
and artificial neural networks for the determination of chlorinated compounds in fish using matrix solid-phase dispersion. Applied Soft Computing, 11: 5155-5164.

[39] Agatonovic-Kustrin, S., Beresford, R. (2000). Basic concepts of artificial neural network (ANN) modeling and its application in pharmaceutical research. Journal of Pharmaceutical and Biomedical Analysis, 22: 717-727.

[40] Desai, K.M., Survase, S.A., Saudagar, P.S., Lele, S.S., Singhal, R.S. (2008) Comparison of artificial neural network (ANN) and response surface methodology (RSM) in fermentation media optimization: Case study of fermentative production of scleroglucan. Biochemical Engineering Journal, 41: 266-273.

[41] Yetilmezsoy, K., Demirel, S. (2008). Artificial neural network (ANN) approach for modeling of $\mathrm{Pb}(\mathrm{II})$ adsorption from aqueous solution by Antep pistachio (Pistacia Vera L.) shells. Journal of Hazardous Materials, 153: 12881300 .

[42] Basha, C.A., Saravanathamizhan, R., Manokaran, P., Kannadasan, T., Lee, C.W. (2012). Photoelectrocatalytic Oxidation of Textile Dye Effluent: Modeling Using Response Surface Methodology. Industrial \& Engineering Chemistry Research, 51: 2846-2854.

[43] Kasiri, M.B., Aleboyeh, H., Aleboyeh, A. (2008). Modeling and Optimization of Heterogeneous Photo-Fenton Process with Response Surface Methodology and Artificial Neural Networks. Environmental Science \& Technology, 42: 7970-7975.

[44] Goel, J., Kadirvelu, K., Rajagopal, C., Garg, V.K. (2005) Removal of Lead(II) from Aqueous Solution by Adsorption on Carbon Aerogel Using a Response Surface Methodological Approach. Industrial \& Engineering Chemistry Research, 44: 1987-1994.
[45] Ghaffari-Moghaddam, M., Yekke-Ghasemi, Z., Khajeh, M., Rakhshanipour, M., Yasin, Y. (2014) Application of response surface methodology in enzymatic synthesis: A review. Russian Journal of Bioorganic Chemistry, 40: 252-262.

[46] Smits, J., Melssen, W., Buydens, L., Kateman, G. (1994) Using artificial neural networks for solving chemical problems: Part I. Multi-layer feed-forward networks. Chemometrics and Intelligent Laboratory Systems, 22:165-189.

[47] Wang, S.-C. (2003). Artificial neural network. In Interdisciplinary Computing in Java Programming; Springer.

[48] Baş, D., Boyacı, İ.H. (2007) Modeling and optimization II: Comparison of estimation capabilities of response surface methodology with artificial neural networks in a biochemical reaction. J. Food Eng. 78: 846-854.

[49] Kocjančič, R., Zupan, J. (1997). Application of a Feed-Forward Artificial Neural Network as a Mapping Device. J. Chem. Inform. Comput. Sci., 37: 985-989.

[50] Istadi, I., Amin, N.A.S. (2006). Hybrid artificial neural network-genetic algorithm technique for modeling and optimization of plasma reactor. Industrial \& Engineering Chemistry Research. 45(20): 6655-6664. 